\title{
EXTRUSION OF CORN GRITS WITH NATIVE OR MODIFIED STARCH ADDITION - INFLUENCE ON STARCH DIGESTIBILITY FRACTIONS, SHEAR STRESS-AT-BREAK, AND EXPANSION RATIO
}

\author{
E. ŠÁrka* ${ }^{a *}$ P. SMrČKovÁa \\ ${ }^{a}$ Department of Carbohydrates and Cereals, University of Chemistry and Technology, Prague, Technicka 5, 16628 \\ Prague 6. Czech Republic \\ ${ }^{\mathrm{b}}$ Engineering Faculty, Mersin University, Çiftlikköy Kampusu 33343 Yenisehir/Mersin. Turkey
}

(Received: 9 April 2015; accepted: 30 June 2015)

\begin{abstract}
The aim of the paper was to seek suitable conditions of extrusion cooking using a laboratory single-screw extruder to increase slowly digestible (SDS) and resistant starch (RS) content in extrudates saving sensory characteristics of the final product prepared from corn grits with added native wheat starch, distarch phosphates, or soluble fibre Nutriose (Roquette, France).

In addition to the composition of input mixtures, process parameters of a single-screw extruder, such as speed of screw and barrel temperatures, were changed. The highest expansion ratio (4.14) was found for temperatures $44{ }^{\circ} \mathrm{C}, 90^{\circ} \mathrm{C}, 120^{\circ} \mathrm{C}$, and $140^{\circ} \mathrm{C}$, die diameter $3 \mathrm{~mm}$, compression ratio 3:1, rotation speed 140 r.p.m., and dosing 15 r.p.m. The addition of native wheat starch to corn grits resulted in values of the expansion ratio ranging from $1.17-2.38$

A high concentration of RS $-2.4 \%$ per starch - was observed for a $20 \%$ ratio of Nutriose with a $10 \%$ addition of water. The addition of $20-50 \%$ of native wheat starch resulted in values ranging from $0.2-0.4 \%$ per starch. The highest SDS content (72.5\% per starch) in extrudates was obtained for the mixture of corn grits, $20 \%$ cross-linked starch, and water (10\% addition).

Keywords: extrusion cooking, wheat starch, distarch phosphate, slowly digestible starch, resistant starch, extrusion process parameters
\end{abstract}

The act of forcing something through an orifice is defined as extrusion, and extrusion cooking is a continuous process defined as the transformation of raw materials into cooked and formed products (FrAmE, 1995). This processing is applied in the food and pharmaceutical industries in order to affect product microstructure, product chemistry, or the macroscopic shape of products, and enables the development of new food products (Š́́rKA et al., 2013). The quality of expanded foods is assessed, e.g. by colour, flavour, crispness, crunchiness, textural analysis, expansion ratio, water absorption and solubility, and pasting properties, which are all related to their expansion (Ali et al., 1996; ChANG et al., 2001; LAZOU et al., 2010; YAO et al., 2011).

The most common objectives of extrusion are to break down starch granules (in which form starch naturally occurs and in which it is isolated from various plants), to render its digestibility and produce a shaped product (WOLF, 2010). In addition to starch polysaccharides amylose and amylopectin, starch granules contain minor amounts of other ingredients, e.g. lipids and proteins (Š́́RKA et al., 2015a). Extrusion cooking of starchy foods causes gelatinisation, partial or complete destruction of the crystalline structure of starch, and protein

* To whom correspondence should be addressed. Phone: +420 22044 3115; fax: +420 220445130; e-mail: evzen.sarka@vscht.cz 
denaturation, as well as the formation of complexes between the starch and lipids and between proteins and lipids. Further, the process leads to molecular weight degradation, with greater degradation occurring at high temperatures, high screw speeds, and lower water content (Donald, 2004). This change ameliorates starch retrogradation.

Starch can be classified as rapidly digestible (RDS), slowly digestible (SDS), or resistant starch (RS) according to its susceptibility to pancreatic amylase (in vitro). RDS is degraded to glucose in 20 min after enzymatic activity. Resistant starch escapes digestion by human enzymes within the small intestine and passes into the colon, where it is metabolised into secondary products by colonic microflora and behaves in a way similar to dietary fibre. It reduces the calorific value of the food and is assumed to have an important role as an agent protecting against colorectal carcinoma. Slowly digestible starch is changed into glucose while being digested in the small intestine for up to $120 \mathrm{~min}$, and has a beneficial physiological effect on the reduction of post-prandial glycemic responses (SMRČKOVÁ et al., 2014).

RS content decreases (digestibility increases) after extrusion processing. From the view of human nutrition - it would be important to have as much RS and SDS in the product as possible, without significantly changing the physical properties such as crispness and crunchiness.

The integrity - and thus digestibility - of starch granules in the extruded product depends on such conditions as water content in the premix, temperature in zones of the extruder, cooking time, pressure, and pH (SINGH et al., 2003). For example low initial water content in raw material for snack foods predetermines that this process will result in products having a high content of slowly digestible starch. The extent of cooking reactions also depends on the construction of the apparatus employed (FrAME, 1995; BRENT, 1999).

The aim of the work was to seek suitable conditions of extrusion cooking using a laboratory single-screw extruder to save or improve the sensory characteristics and nutritional properties of the final product compared with incoming corn grits and mixtures with added native wheat or chemically modified starch.

\section{Materials and methods}

\subsection{Materials}

Fine corn grits were provided by the Konkordia Ltd. corn mill, Mrzkovice, Czech Republic. High-grade wheat A-starch (Amylon Havlíčkův Brod, Czech Republic), Moramyl ZBH (MZBH) distarch phosphate (P $0.98 \mathrm{~g} \mathrm{~kg}^{-1} \mathrm{DM}$; Krnov Ltd. starch factory, Czech Republic), PU-91-088 distarch phosphate (P $0.05 \mathrm{~g} \mathrm{~kg}^{-1}$ DM; Lyckeby, Sweden), and Moramyl ZB (MZB) pregelatinised distarch phosphate (P $2.50 \mathrm{~g} \mathrm{~kg}^{-1} \mathrm{DM}$; Krnov Ltd. starch factory, Czech Republic) were applied. Additionally we used the soluble fibre Nutriose FM 06 provided by Roquette, France.

Pancreatic $\alpha$-amylases (3 Ceralpha $\mathrm{U} \mathrm{mg}^{-1}$ ), amyloglucosidase (3260 $\mathrm{U} \mathrm{ml}^{-1}$ on soluble starch), invertase (300 $\left.\mathrm{U} \mathrm{mg}^{-1}\right)$, and a glucose oxidase/peroxidase colorimetric assay kit (GOPOD) were purchased from Megazyme International Ireland Ltd.

\subsection{Extrusion process}

Initially, the corn grits were combined in a kitchen mixer with native wheat or modified starch $(0,100,200$, or 500 grams per $\mathrm{kg}$ of mixtures) in a dry state. The input mixtures 
differed in composition and water addition $(5,10$, and $20 \%$, w/w). A single-screw laboratory extruder, the Kompaktextruder Brabender KE 19/25 (Brabender, Duisburg, Germany), having a $19 \mathrm{~mm}$ barrel diameter and a 25:1 barrel length-to-diameter ratio, was used for extrusion. The barrel of the extruder was heated by 3 controlled zones and by an additional one in the head. Temperatures in the barrel sections were kept constant during extrusion; the temperature of the head was set in the range of $100-160{ }^{\circ} \mathrm{C}$, while the revolutions of the screw of the compression ratios 2:1 or 3:1 were set at 80-150 r.p.m. The dosing speed of prepared corn samples was in the range of 15-20 r.p.m. (feed rate in the range of 2.11-2.44 $\left.\mathrm{kg} \mathrm{h}^{-1}\right)$. The die had a diameter of $3 \mathrm{~mm}$ or $4 \mathrm{~mm}$. The extrudates were cooled to room temperature and sealed in plastic bags for follow-up measurements.

\subsection{Methods}

Total starch content was quantified enzymatically by a Megazyme Total starch assay kit (AACC, 1976; AOAC, 1996). The SDS fractions were measured according to the enzymatic procedure of ENGLYST and co-workers (1992) modified by OVANDO-MARTínEZ and co-workers (2011). Determination of the resistant starch was carried out using the Megazyme Resistant starch assay kit commercial procedure (AACC, 2002; AOAC, 2002).

Diameter measurement of the product was made using a digital calliper at 10 points of the extrudate and averaged. The expansion ratio (ER) of the puffed product was calculated according to FrAME (1995):

$$
E R=D / d,
$$

where $D$ : diameter of product, $d$ : diameter of die opening.

Additionally, the extrudates were tested on the Instron 5500 device (USA) connected to a controlling computer system, which enabled data storage and evaluation of the measurement of shear stress-at-break.

\section{Results and discussion}

The "results and discussion" section provides only part of the results obtained in 64 experiments, i.e. only those that show selected influences on product parameters. We changed the arrangement of the device, revolutions of the screw, ratio of the added starch, temperatures of zones, etc. The design of experiments for $\mathrm{d}=4 \mathrm{~mm}$ was published elsewhere (Š́rRKA et al., 2015b), where influence of extrusion conditions on RS content where discussed. The measured data were completed by SDS analyses and further experiments were done for $\mathrm{d}=3$ $\mathrm{mm}$, where better results were expected.

\subsection{Influence of the arrangement of the extruder}

The influence of the chosen screw and die on the expansion ratio was tested for these parameters: zone temperatures: $45^{\circ} \mathrm{C}, 85^{\circ} \mathrm{C}, 122^{\circ} \mathrm{C}, 143{ }^{\circ} \mathrm{C}$, revolutions of dosing screw 15 r.p.m., and revolutions of barrel screw 120 r.p.m. The expansion ratio (and pressure in the extruder) had higher values for the 3:1 compression ratio and $3 \mathrm{~mm}$ die when compared with the 2:1 compression ratio and $4 \mathrm{~mm}$ die (data not shown). The resistant starch and SDS starch contents were for these compression ratios and the same starting raw material (corn grits $+5 \%$ water addition) $-0.1 \%$ and $57 \%$, respectively. 


\subsection{Influence of screw revolutions on the flow of extrudate}

The higher was the revolution of the screw, the lower was the pressure in it (Fig. 1). This process was accompanied by heat generation (the temperature in the $3^{\text {rd }}$ zone rose from 116 to $121^{\circ} \mathrm{C}$ with increasing revolutions).

The influence of screw revolutions on the flow of extrudate is illustrated in the same figure. The amount of extrudate per minute did not depend on the revolutions significantly. Fluidity of the melt probably caused slowing down of the flow and backward flow in the extruder barrel as well. Velocity distribution is closely related to the rheological properties of the material. Therefore, by knowing how changes in rheological properties may modify the velocity distribution, it becomes possible to study how the flow characteristics change (Ponomarev et al., 2012).

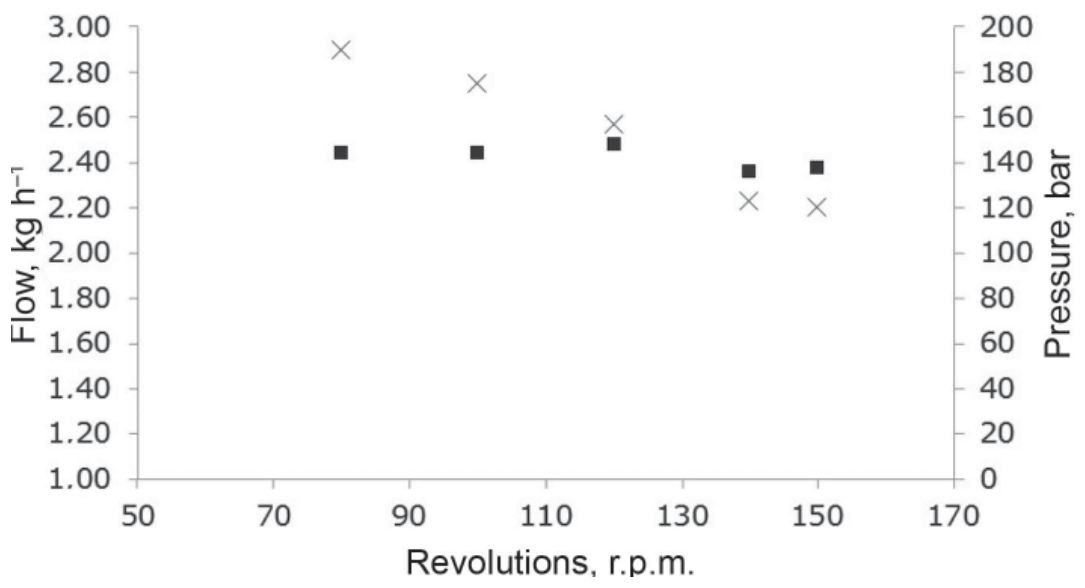

Fig. 1. Influence of screw revolutions on the flow of the extrudate and pressure in the extruder; zone temperatures: $50{ }^{\circ} \mathrm{C}, 90^{\circ} \mathrm{C}, 116-121^{\circ} \mathrm{C}, 140{ }^{\circ} \mathrm{C}$, die $4 \mathrm{~mm}$, compression ratio $1: 1$, revolutions of dosing screw 15 r.p.m., corn grits and $10 \%$ of water; $\square$ :flow, x: pressure

\subsection{Effect of temperature of the head}

The temperature of zone 1 was set to $45-50{ }^{\circ} \mathrm{C}$; zone 2 to $83-90{ }^{\circ} \mathrm{C}$; zone 3 to $100-120{ }^{\circ} \mathrm{C}$, head to $100-160{ }^{\circ} \mathrm{C}\left(\mathrm{t}_{4}\right)$. Figure 2 shows the influence of $\mathrm{t}_{4}$ on the expansion ratio of two premixes with different mass ratio of water and added modified starch, the two experiment arrangements were done for various ranges of $t_{4}$. The trend is very similar; expansion ratio increases with increased temperature, but we can see on the graphs that the climb is slower for $\mathrm{t}_{4} \geq 130^{\circ} \mathrm{C}$. Increasing puffing at higher temperatures was found by CHAKRABORTY and BANERJEE (2009) for expanded green gram as well. Based on their measured data, PAI and co-workers (2009) explained that low shear viscosity of the melt is important for good expansion.

RS content is often decreased after extrusion cooking. But according to our results, the higher temperature caused a slight increase in resistant starch content (data not shown). It confirms our previous data (ك̌́́RKA et al., 2015b) that final temperature is not a decisive factor for RS creation. HutH and co-workers (2000) reported that extrusion cooking parameters and subsequent storage affected the generation of RS in extruded barley flour. They observed the highest RS formation of up to $6 \%$ in extruded barley flours after extrusion cooking at a mass temperature of $150^{\circ} \mathrm{C}$. 

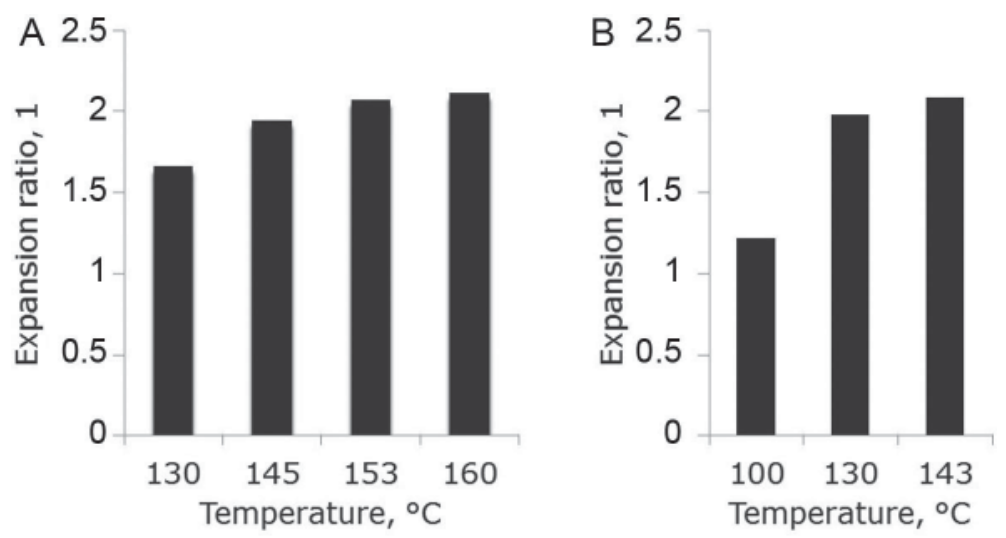

Fig. 2. Influence of temperature of the head on expansion ratio of the extrudate; compression ratio of the screw 2:1, die 4 mm, revolutions of dosing screw 15 r.p.m., revolutions of barrel screw 120 r.p.m., premix: A: corn grits $+5 \%$ water addition; A: corn grits $(80 \%)+\mathrm{MZBH}(20 \%)+10 \%$ water addition.

\subsection{Effect of water addition to the premix}

Figure 3 illustrates the influence of water content in the premix on the expansion ratio (ER). In all cases (with the exception of sample 4), the lower the water content, the higher the expansion ratio is. Chinnaswamy and Hanna (1988) reported that low moisture content of starches may restrict flow inside the extruder barrel, increases shear rate and residence time, which could perhaps increase degree of starch gelatinization and expansion, which could be linked to higher expansion ratio. However, the process seems to be more complex.

In case of sample 4 (addition of soluble fibre Nutriose FM 09), no differences in ER were observed and the expansion ratio equalled 1.0.

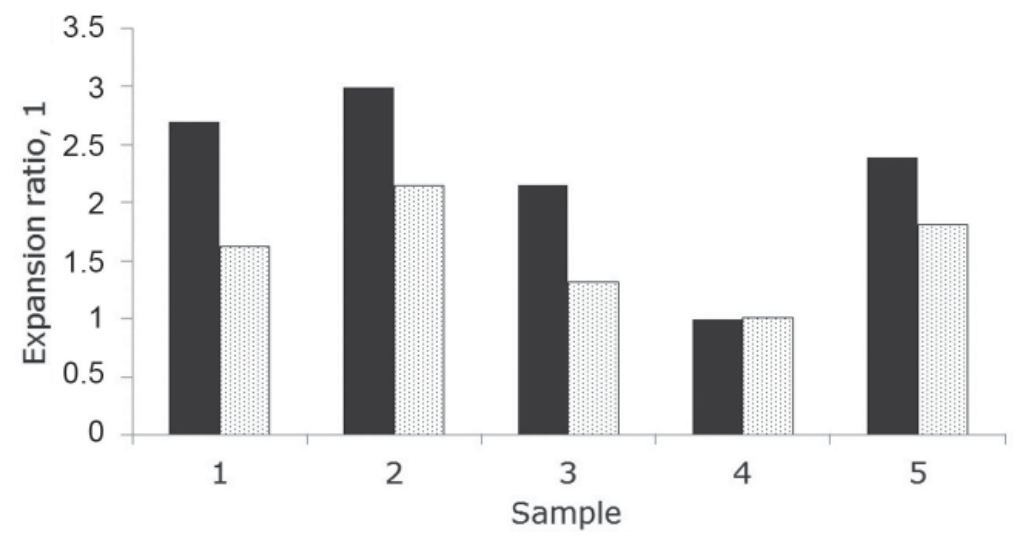

Fig. 3. Influence of water content on expansion ratio of the extrudate; samples: 1: corn grits; 2: corn grits $(90 \%)+\mathrm{MZBH}(10 \%) ; 3$ : corn grits $(80 \%)+\mathrm{MZB}(20 \%) ; 4$ : corn grits $(80 \%)+\mathrm{FM} 06(20 \%)$; 5 : corn grits $(80 \%)+$ wheat starch $(20 \%)$; zone temperatures: samples $1-2: 45-48{ }^{\circ} \mathrm{C}, 83-88{ }^{\circ} \mathrm{C}, 120{ }^{\circ} \mathrm{C}, 140{ }^{\circ} \mathrm{C}$, samples $3-5$ : $46-50{ }^{\circ} \mathrm{C}, 90^{\circ} \mathrm{C}, 100-110{ }^{\circ} \mathrm{C}, 130{ }^{\circ} \mathrm{C}$; die $4 \mathrm{~mm}$, compression ratio 2:1, revolutions of dosing screw 15 r.p.m., revolutions of barrel screw: samples 1-2: 120 r.p.m.; samples 3: 580 r.p.m.; $\square$ : 5\% water addition; 圈: 10\% water addition 
The influence of water content in the premix on resistant starch and on slowly digestible starch content is shown in Figure 4. In all cases (with the exception of Nutriose addition), the resistant starch was approximately the same, with $0.1 \%$ as the measurement error. The $20 \%$ ratio of the soluble fibre Nutriose FM 09 in the premix caused increased resistant starch content, depending on the water content. SDS content was high $(>50 \%)$ in all cases; moreover, the lower the water content, the higher the SDS content was.
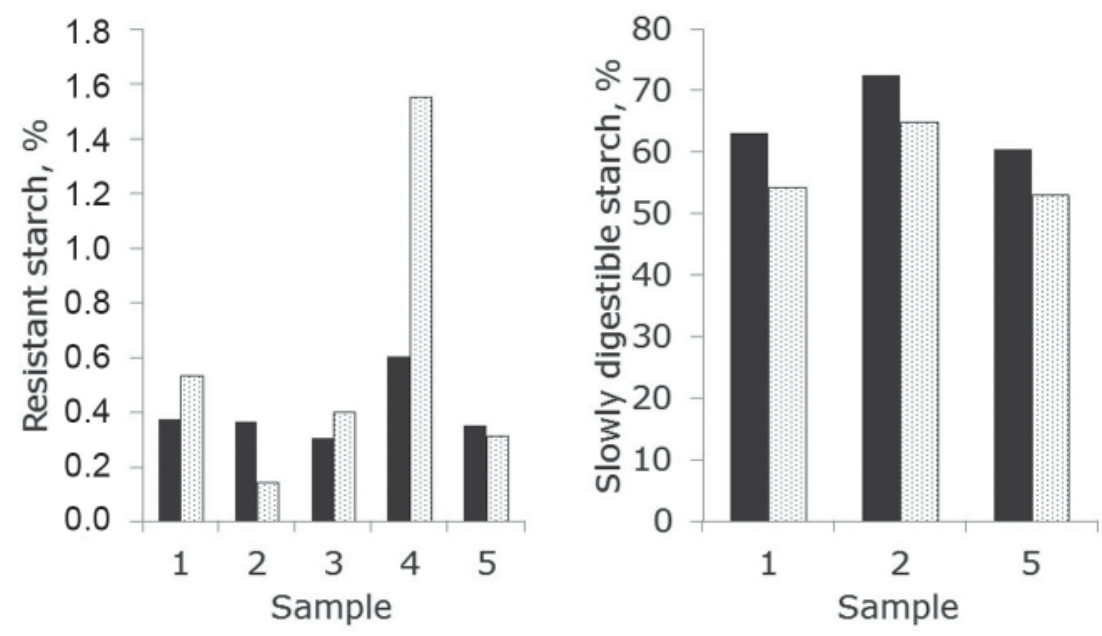

Fig. 4. Influence of water content on resistant starch and slowly digestible starch content of the extrudate; samples: 1: corn grits; 2 : corn grits $(90 \%)+\mathrm{MZBH}(10 \%)$; 3: corn grits $(80 \%)+\mathrm{MZB}(20 \%)$; 4: corn grits $(80 \%)+\mathrm{FM} 06$ $(20 \%)$; 5 : corn grits $(80 \%)+$ wheat starch $(20 \%)$; for reaction conditions see Fig. 3 ; $\mathbf{\square}$ : $5 \%$ water addition; : $: 10 \%$ water addition

\subsection{Effect of starch additives to the premix}

Figure 5 illustrates the influence of the ratio of individual starch additives to the premix on the expansion ratio. The composition of premixes for extrusion was: a: corn grits, b: corn grits+MZBH, c: corn grits+MZB, d: corn grits+FM 06, e: corn grits+PU-91-088, f: corn grits + wheat starch. Because better results were gained for lower water content, results for the 5\% water addition are presented here (omitting those for the premix containing PU-91-088, where it was $10 \%$ ). Different behaviour was observed when puffed products were shaped: when incoming starch was in the form of intact granules, higher addition of starchy material decreased the expansion ratio (samples b and f); on the other hand, a higher ratio of pregelatinised modified starch caused an increase in the expansion ratio. The explanation may be in water competition between the demand for starch gelatinisation and fibre. When compared with pure corn grits, both the soluble fibre Nutriose FM 09 and PU-91-088 decreased the expansion ratio in both concentrations. 

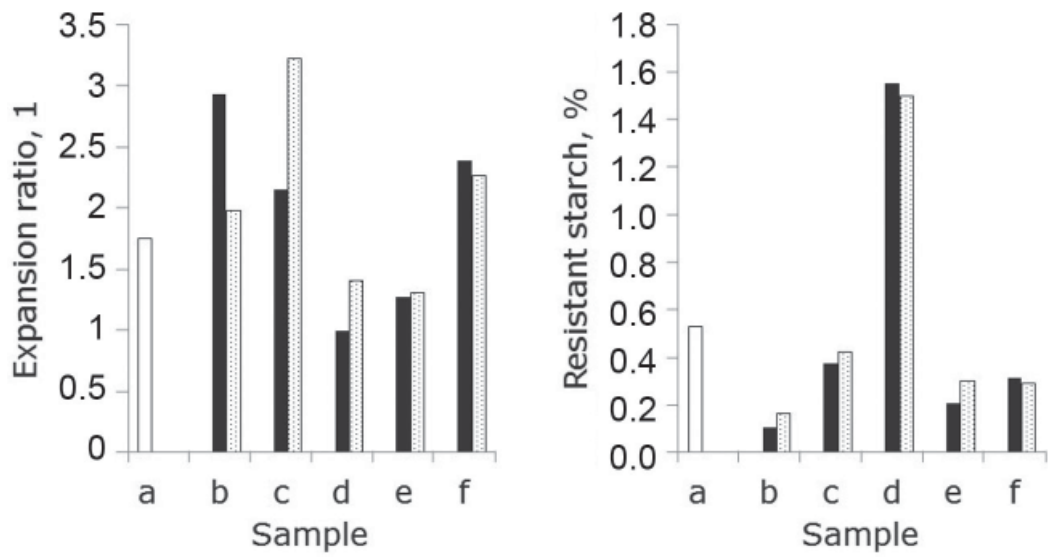

Fig. 5. Influence of mass fraction of various additives in the premix on the expansion ratio and resistant starch content in extrudates. Input materials: a: corn grits; b: corn grits $+\mathrm{MZBH}$; c: corn grits $+\mathrm{MZB}$; d: corn grits $+\mathrm{FM} 06$; e: corn grits+PU-91-088; f: corn grits+wheat starch; zone temperatures: $46-51{ }^{\circ} \mathrm{C}, 89-94{ }^{\circ} \mathrm{C}, 110-112{ }^{\circ} \mathrm{C}$,

$130-133^{\circ} \mathrm{C}$, die $4 \mathrm{~mm}$, compression ratio 2:1, revolutions of dosing screw 15 r.p.m., revolutions of barrel screw 80 r.p.m.; mass ratio of individual starch additives: ㅁ: $20 \%$ or $130 \%$

The influence of additives on resistant starch content is shown in Figure 5 as well. Very low RS content $(<0.2 \%)$ was observed for the addition of $20 \%$ and $50 \% \mathrm{MZBH}$. The addition of the soluble fibre Nutriose FM 09 in the premix caused an increase in resistant starch. This effect can be explained by lower viscosity of the melt because of low-molecular weight of Nutriose (Mw $4400 \mathrm{Da})$.

\subsection{The dependence of shear stress-at-break on the extrusion ratio}

The better puffing of the extrudate is linked to a higher expansion ratio and to lower shear stress-at-break. The dependence is shown in Figure 6. The dependence can be transformed into a linear form between $1 / \tau$ and (ER-1) for ER $>2$, where $\tau$ is shear stress-at-break. The relation is in agreement with the data of CHOUDHARY and GAUTAM (1999) for extrudates of rice flour.

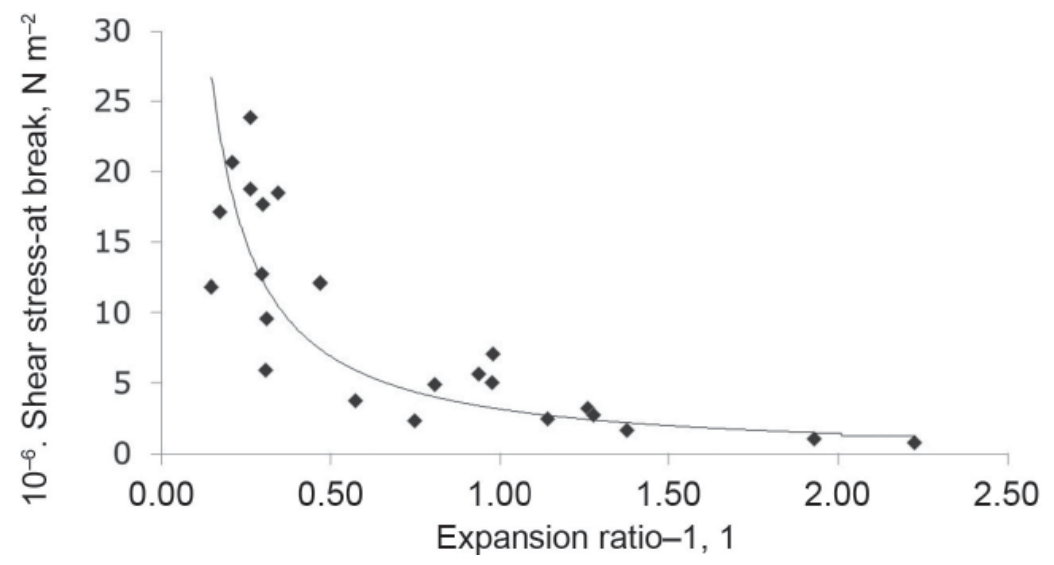

Fig. 6. Dependence of shear stress-at-break on expansion ratio 


\section{Conclusions}

Extrusion process parameters strongly affect the quality of extrudates, and they have been the focus of most studies on the extrusion processing of various foodstuffs. Our previous work has shown that physicochemical properties of raw corn also affect extrudate quality (KLJAK et al., 2015). Furthermore, a suitable starch additive was tested.

The highest expansion ratio (4.14) and the lowest shear stress were found for the pure corn grits with a $5 \%$ water addition and the following process parameters: temperatures in the extruder $44{ }^{\circ} \mathrm{C}, 90^{\circ} \mathrm{C}, 120^{\circ} \mathrm{C}$, and $140{ }^{\circ} \mathrm{C}$, die diameter $3 \mathrm{~mm}$, compression ratio $3: 1,140$ r.p.m., dosing 15 r.p.m., pressure 250 bar. A $20-50 \%$ ratio of distarch phosphate (MZBH) in the premix increased the expansion ratio. The addition of $20-50 \%$ of the native wheat starch resulted in values of the expansion ratio ranging between 1.17-2.38, depending on process parameters and water addition.

During the extrusion process, the level of RDS slowly increased and that of RS slowly decreased in all samples. A high concentration of resistant starch $-2.4 \%$ per starch - was observed for the $20 \%$ ratio of Nutriose (Roquette, France) using $10 \%$ water. The addition of $20-50 \%$ of native wheat starch resulted in values of resistant starch ranging between $0.2-0.4 \%$ per starch. The highest SDS content ( $72.5 \%$ per starch) and $1.1 \%$ per starch of RS in the extrudates was obtained for the mixture of corn grits, $20 \%$ cross-linked starch MZBH, and water ( $10 \%$ addition).

Our results demonstrate that a suitable starch additive based on physicochemical properties may improve the sensory characteristics and nutritional quality of extrusion products.

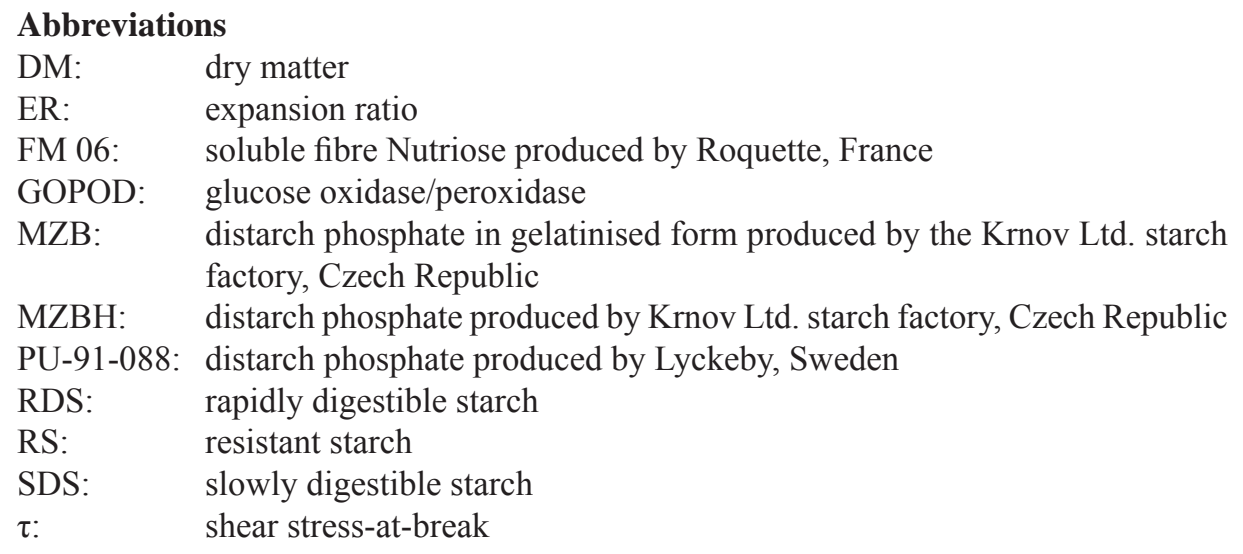

This research was supported by the "Wheat with specific starch composition and features for food and non-food purposes" QJ1310219 research grant of the Czech Ministry of Agriculture.

\section{References}

AACC (1976): Total starch assay procedure, (Megazyme Amyloglucosidase/alpha-Amylase Method), AACC Inc., St. Paul, Minnesota, Method 76-13. 
AACC (2002): Resistant starch in starch samples and plant materials. AACC Inc., St. Paul, Minnesota, Method 32-40.01

AOAC (1996): Starch (total) in cereal products. Official method 996.11 AOAC Inc., Gaithersburg, Maryland.

AOAC (2002): Resistant starch in starch and plant materials. Enzymatic digestion. Official Method 2002.02. First action 2002. AOAC Inc., Gaithersburg, Maryland

Ali, Y., Hanna, M.A. \& Chinnaswamy, R. (1996): Expansion characteristics of extruded corn grits. LWT - Food Sci. Technol., 29, 702-707.

BREnT, J.L. (1999): Principles of extrusion cooking technology: Single- and twin-screw extruders. -in: Chang, Y. K. \& Wang, S.S. (Eds) Advances in extrusion technology. Technomic Publishing Company Inc., Pennsylvania, pp. 73-75.

Chakraborty, P. \& BanerJeE, S. (2009): Optimization of extrusion process for production of expanded product from green gram and rice by response surface methodology. J. Sci. Ind. Res., 68, 140-148.

Chang, Y.K., Hashimoto, J.M., Acioli-Moura, R., Martinez-Flores, H.E. \& Martinez-Bustos, F. (2001): Influence of extrusion conditions on cassava starch and soybean protein concentrate blends. Acta Alimentaria, 30, 189203.

Chinnaswamy, R. \& Hanna, M.A. (1988): Relationship between amylose content and extrusion expansion properties of corn starches. Cereal Chem., 65, 138-143.

ChoudhaRY, G.S. \& Gautam, A. (1999): Characteristics of extrudates produced by twinscrew extrusion of rice flour. J. Food Sci., 64, 480-487.

Donald, A.M. (2004): Understanding starch structure and functionality. -in: Eliasson, A.-C. (Ed.) Starch in food. Structure, function and applications. Woodhead Publishing Limited, Cambridge, pp. 171-199.

Englyst, H.N., Kingman, S.M. \& Cummings, J.H. (1992): Classification and measurement of nutritionally important starch fractions. Eur. J. Clin. Nutr., 46, S33-S50.

Frame, N.D. (1995): The technology of extrusion cooking. Blackie Academic \& Professional, London, Glasgow, New York, Tokyo, Melbourne, Madras, pp. 1-38, 185.

Huth, M., Dongowski, G., Gebhard, E. \& Flamme, W. (2000): Functional properties of dietary fibre enriched extrudates from barley. J. Cereal Sci., 32, 115-128.

KlJak, K., Šárka, E., Dostálek, P., SmrČKové, P. \& Grbeša, D. (2015): Influence of physicochemical properties of Croatian maize hybrids on quality of extrusion cooking. LWT - Food Sci. Technol., 60, 472-477.

Lazou, A., Krokida, M. \& Tzia, C. (2010): Sensory properties and acceptability of corn and lentil puffs. J. Sens. Stud., 25, 838-860.

Ovando-Martínez, M., Osorio-Díaz, P., Whitney, K., Bello-Pérez, L.A. \& Simsek, S. (2011): Effect of the cooking on physicochemical and starch digestibility properties of two varieties of common bean (Phaseolus vulgaris L.) grown under different water regimes. Food Chem., 129, 358-365.

Pai, D.A., Blake, O.A., Hamaker, B. R., Campanella, O.H. (2009): Importance of extensional rheological properties on fiber-enriched corn extrudates. J. Cereal Sci., 50, 227-234.

Ponomarev, D., Rodier, E., Sauceau, M., Nikitine, C., Mizonov, V. \& Jacques, F. (2012): Modelling nonhomogeneous flow and residence time distribution in a single-screw extruder by means of Markov chains. J. Math. Chem., 50, 2141-2154.

Š́́rKA, E., ČopíKOVÁ, J. \& SMRČKovÁ, P. (2013): Extruzní proces v cereální a cukrovinkářské technologii (Extrusion process in cereal and confectionery technologies). Listy cukrov. a řep., 129, 350-354.

Šárka, E., Hrabal, R., KolÁčeK, J., SmrČKovÁ, P. \& Bubní, Z. (2015a). Využití 31P NMR ke kvantitativní analýze fosforečnanového diesteru škrobu a určení mechanismu reakce (The use of 31P NMR for quantitative analysis of distarch phosphate and determination of the reaction mechanism). Chemické Listy, 109, 204-209.

Šárka, E., SmrčKová, P., Chena Aldao, D.A., SaĞlamtaș, M., Koláček, J. \& Pour, V. (2015b): Influence of process parameters and added starches on resistant starch content and sensory properties of maize extrudates. Starch/ Stärke, 67(9-10), 737-744.

Singh, N., Singh, J., KAUR, L., Sodhi, N.S. \& Gill, B.S. (2003): Morphological, thermal and rheological properties of starches from different botanical sources. Food Chem., 81, 219-231.

SmrČ́ová, P., Saglamtas, M., Hofmanová, T., Koláček, J., Chena, D. \& ŠÁrka, E. (2014): Extrusion of corn grits with native or modified starch addition - influence of process parameters on digestibility, shear stress and expansion ratio. Czech J. Food Sci., 32, 503-508.

Wolf, B. (2010): Polysaccharide functionality through extrusion processing. Curr. Opin. Colloid In., 15, 50-54.

YaO, N., EKenstedt, K.L. \& White, P. J. (2011): Textural properties of food systems having different moisture concentrations as impacted by oat bran with different $\beta$-glucan concentrations. J. Texture Stud., 42, 359-368. 